\title{
A GARANTIA DOS DIREITOS HUMANOS NA FORMAÇÃO ESCOLAR: ATUAÇÃO DA GESTÃO EDUCACIONAL E ENFRENTAMENTOS AOS DILEMAS DO COTIDIANO ESCOLAR
}

Alexandre Cesar Rodrigues da Silva ${ }^{1}$ Maria do Carmo de Oliveira Nogueira ${ }^{2}$

SILVA, A. C. R. da; NOGUEIRA, M. do C. de O. A garantia dos direitos humanos na formação escolar: Atuação da gestão Educacional e enfrentamento aos dilemas do cotidiano escolar. EDUCERE - Revista da Educação, Umuarama, v. 18, n. 2, p. 357-371, jul./dez. 2018.

RESUMO: O presente artigo tem por finalidade discutir a questão dos Direitos Humanos a partir das garantias estabelecidas pelas legislações educacionais nacionais, bem como de conceituar estes direitos vinculados à formação educacional escolar e ainda discorrer sobre a importância da atuação dos gestores educacionais na aprendizagem e manutenção destes direitos como formação básica. Desta forma serão utilizados resultados de materiais bibliográficos que abordam as questões dos Direitos Humanos no cotidiano escolar, onde a demanda exigida das escolas sobre este tema tem cada vez mais um grau de importância na formação humana e dos profissionais que nela atuarão.

PALAVRAS-CHAVE: Cotidiano Escolar; Direitos Humanos: Gestão Educacional.

\section{THE GUARANTEE OF HUMAN RIGHTS AT SCHOOL: EDUCATIONAL MANAGEMENT ATTITUDES WHEN FACING DAILY SCHOOL LIFE DILEMMAS}

ABSTRACT: This article aims at discussing the issue of Human Rights based on guarantees set forth in the Brazilian educational legislation, as

DOI: 10.25110 /educere.v18i2.2018.6975

${ }^{1}$ Acadêmico do Curso de Pedagogia da UNIPAR_ Universidade Paranaense. (Rua Fernando sabino, Cj Sonho Meu, No 1741, Umuarama/Paraná) cezarbedoya@hotmail.com

${ }^{2}$ Mestre em Educação pela Universidade Federal de Uberlândia - UFU (2001). Atualmente é professora titular - regime Tempo Integral da Universidade Paranaense. 
well as to conceptualize the rights linked to school education and discuss the importance of the role of educational managers in the learning and maintenance of these rights as basic training. A bibliographic review on materials that address the issues of Human Rights in the daily school life will be developed, where the demand required from the schools on this matter is becoming increasingly important in the human formation and in the formation of the professionals who will work in it.

KEYWORDS: Daily School Life; Human Rights; Educational Management.

\section{LA GARANTÍA DE LOS DERECHOS HUMANOS EN LA FORMACIÓN ESCOLAR: ACTUACIÓN DE LA GESTIÓN EDUCACIONAL Y ENFRENTAMIENTOS A LOS DILEMAS DEL COTIDIANO ESCOLAR}

RESUMEN: El presente artículo tiene por finalidad discutir la cuestión de los Derechos Humanos a partir de las garantías establecidas por las legislaciones educativas nacionales, así como de conceptualizar estos derechos vinculados a la formación educativa escolar y aún discurrir sobre la importancia de la actuación de los gestores educativos en el aprendizaje y el mantenimiento de estos derechos como formación básica. De esta forma se utilizarán resultados de materiales bibliográficos que abordan las cuestiones de los Derechos Humanos en el cotidiano escolar, donde la demanda exigida de las escuelas sobre este tema tiene cada vez más un grado de importancia en la formación humana y de los profesionales que en ella actuarán.

PALABRAS CLAVE: Cotidiano Escolar; Derechos humanos; Gestión Educativa.

\section{INTRODUÇÃO}

Direitos humanos não é um assunto tão recente no mundo, começou a ser discutido logo após o fim da Segunda Guerra Mundial. A Declaração Universal dos Direitos Humanos, que apresenta os direitos humanos básicos, foi adotada pela Organização das Nações Unidas - ONU em 10 de dezembro de 1948. A partir desta data ela começou a valer e a ser aplicada aos poucos no mundo. Em relação à educação no Brasil, os 
direitos humanos como conteúdo tratado no Plano Nacional passa a estar presente a partir do Decreto de $\mathrm{n}^{0} 7.037$, de 21 de dezembro de 2009. Por força legal e no desenrolar deste cenário a escola por sua vez, passa a ter o dever de ajudar o sujeito a compreender os princípios de igualdade e de equidade, bem como a criar sua autonomia. Este modelo de educação está baseado na CF de 1988, mas a escola ainda hoje, enfrenta vários dilemas em decorrência a não totalidade da formação para os direitos humanos.

Muitas escolas encontram-se ainda arraigadas ao modelo de escola bancária, por várias circunstâncias, entre elas pela má formação e capacitação dos professores; desvios dos propósitos da capacitação em serviço; falta de perfil de liderança dos gestores educacionais; acúmulos de funções e cargos, e até mesmo o que deveria se apresentar como propostas e normas escolares para ajudar na formação educacional / escolar em direitos humanos e deveres acaba atrasando ou deixando mais complicado essa situação, que é o caso de um PPP (Projeto Político - pedagógico) das escolas mal elaborados. A gestão educacional tem o papel fundamental de ajudar e coordenar todos os processos para uma solução efetiva.

O propósito deste artigo é discutir a questão dos direitos humanos, a forma como são trabalhados no ambiente escolar e como são garantidos para a formação dos indivíduos a partir da atuação dos gestores e professores na dinâmica cotidiana das escolas.

Para tanto, se faz necessário entender o que determina o Decreto de $\mathrm{N}^{0}$ 7.037, de 21 de dezembro de 2009. Este decreto desenvolve uma base para como a escola deve seguir a aplicação dos conteúdos sobre os direitos humanos em suas matrizes escolares, é também um guia para auxiliar os gestores durante este processo. A advogada e especialista em Direito Público, Carneiro comenta a seguinte ideia sobre este decreto:

Pautado na necessidade de reforço do Estado Democrático de Direito, aliado à integração e ampliação de diversos setores, previstos na Constituição de 1988, principalmente quanto aos princípios e garantias fundamentais, o Poder Executivo baixou o Decreto $\mathrm{n}^{\circ} .7 .037 / 2009$, de 21 de dezembro de 2009, que aprova o Programa Nacional de Direitos Humanos - PNDH-3. Estão contidos em seu bojo, eixos 
orientadores e importantes diretrizes, que dependem da aprovação pelo Plenário. Tão importantes, que a força da aprovação das leis trará significantes mudanças na vida de todos os brasileiros. (CARNEIRO, 2010, p. 50).

Esse decreto vem para ajudar na educação e para finalmente colocar uma base de apoio legal aos educadores para ampliar conhecimentos dos alunos à luz de seus direitos e deveres.

Em segunda instância, precisamos compreender as dinâmicas do ambiente escolar que corroboram para a aprendizagem sobre os direitos humanos, bem como levantar situações que levam a privação desses direitos, principalmente no que tange a atuação dos gestores.

Portanto, a presença de gestores qualificados com formação pedagógica e com olhares e atuações diferenciadas promove no ambiente escolar a formação para os direitos básicos, bem como se efetiva o processo de aquisição destes conhecimentos por parte dos alunos ao se compreenderem sujeitos de direitos e deveres, para fortalecer neles a compreensão dos princípios de igualdade e de equidade, bem como a criar sua autonomia.

\section{PRINCIPAIS SITUAÇÕES QUE OCORREM NAS ESCOLAS QUE FEREM OS PRINCÍPIOS DOS DIREITOS HUMANOS}

Como é realmente a vida no ambiente escolar? Será que todos os direitos são realmente respeitados? Os alunos cumprem seus deveres? Como é realmente esse ambiente? Todos que têm filhos na escola ou que já estiveram nesse cenário sabem que isso é relativo na dinâmica de cada escola. Cada ambiente possui uma equipe pedagógica que coordena este lugar e seus alunos. Sabe-se que cada escola é diferente, por mais que esta seja uma vinculada à uma rede com o mesmo nome e princípios elas são bem distintas umas das outras.

Mas, um ponto que todos sabem aos quais elas podem ser iguais é quando se trata dos problemas, os mais comuns: bullying; uso de álcool e outras drogas; o preconceito contra o gordo; étnico- racial; orientação sexual; religião, além de muitas outras mazelas sociais que também perpassam intramuros das escolas, algo preocupante como o racismo; a 
gravidez na adolescência; o grande tabu quando se trata em alertar sobre doenças sexualmente transmissíveis; a destruição do mobiliário escolar; o porte de armas, entre tantos outros problemas que as escolas enfrentam no seu dia a dia.

Então, o que fazer, como solucionar estes problemas? Qual é a melhor solução? De quem é o trabalho de fiscalizar e monitorar essa área?

Heloisa Lück em um de seus textos comenta sobre esse tema e aponta como deve ser a atuação do diretor escolar:

Uma das competências básicas do diretor escolar é promover na comunidade escolar o entendimento do papel de todos em relação à educação e a função social da escola, mediante a adoção de uma filosofia comum e clareza de uma política educacional, de modo a haver unidade e efetividade no trabalho de todos. O desenvolvimento dessa concepção passa pelo estudo contínuo de fundamentos, princípios e diretrizes educacionais, postos tanto na legislação educacional, que define os fins da educação brasileira e organiza, orienta a sua atuação, quanto na literatura educacional de ponta e atual. (LÜCK 2001, pg. 18 - 19 apud PENIN, 2001, p.18).

Como foi comentado pela autora existem vários meios que são construídos para orientar e ajudar os educadores nessa jornada, bem como, o gestor educacional / escolar, deve, em seu dia a dia, implementar ações e projetos como: "Roda de conversas", para compreensão desta dinâmica interna da escola, para levantamentos das ocorrências e busca de soluções locais para solucioná-las. Para isso, co-gestoramente possibilitar a formação contínua de sua equipe pedagógica, de professores e demais profissionais da escola, fortalecendo o sentimento de pertença deste grupo no processo como corresponsáveis na formação dos seus estudantes, e pelas possibilidades de atualizações e diálogos contínuos e permanentes. A legislação mais recente corrobora com tal prática e abrange, em particular, os Direitos Humanos no plano escolar, conforme Decreto $n^{0}$ 7.037.

\subsection{Decreto de $n^{0} \mathbf{7 . 0 3 7}$ e seus principais pontos}

O decreto $n^{\circ} 7.037$ de 21 de dezembro de 2009 veio para aprovar 
o Programa Nacional de Direitos Humanos - PND-3, implantado de acordo com os eixos orientadores e suas diretrizes.

O PNDH foi construído em seis grandes eixos orientadores, subdivididos em 25 diretrizes e com 82 objetivos estratégicos que se entregam ou representa os sete eixos, as 36 diretrizes e as 700 resoluções da $11^{\mathrm{a}} \mathrm{CNDH}$. O plano também possui como base de sua fundamentação, as resoluções das conferências nacionais temáticas, os Planos e Programas do governo federal, os tratados internacionais elaborados pelo Estado brasileiro e as recomendações dos comitês de monitoramento de tratados da ONU e dos relatórios especiais.

O primeiro eixo orientador, aborda o tema da interação democrática entre o estado e a sociedade civil. Tem início na diretriz de número 1 e se encerra na de número 3. Tem como base de sua ideia realizar um compromisso de todos e a participação social na continuação de projetos para monitorar as políticas públicas, que são essenciais para que ocorra a efetivação dos direitos humanos, seja substantivo e que venha de uma verdadeira democracia.

O segundo eixo orientador reflete sobre o desenvolvimento e os Direitos Humanos. Tem seu início na diretriz de número 4 e se encerra na de número 6. Neste eixo a ideia é voltada para a inclusão social e a garantia do cidadão poder exercer sua cidadania. Também visa ao desenvolvimento local e territorial e busca um crescimento sustentável capaz de prevenir os direitos fundamentais das próximas gerações.

O terceiro eixo orientador tem suas ideias sobre o tema: A universalização em um contexto de desigualdades. Começa na diretriz de número 7 e se encerra na de número 10. Seu principal foco sobre a necessário de conhecer as diferenças e as diversidades, para que se possa chegar no princípio da igualdade com a visão de superar as barreiras estruturais para poder acessar os Direitos Humanos.

O quarto eixo orientador traz os temas: Segurança pública, acesso à justiça e o combate à violência. Tem seu início na diretriz de número 11 e se encerra na de número 17. Esse eixo traz metas para prevenir e diminuir a violência e a criminalidade, dando enfoque na transparência dessa meta com ajuda e a participação da população. Também elabora medidas para ampliar o acesso à justiça, informando melhor a população e também comenta que é necessária a modernização da gestão do sistema 
da justiça.

O quinto e penúltimo eixo traz os temas sobre a educação e a cultura em Direitos Humanos. Tem seu início na diretriz de número 18 e se encerra na de número 22. Este se baseia na formação do cidadão com uma consciência em relação ao seu próximo, na tolerância, na compaixão e com o compromisso contra todas as formas de discriminação, opressão e violência, com seus fundamentos no respeito à dignidade humana.

O sexto e último eixo orientador tem seu tema sobre o Direito à memória e à verdade. Se inicia na diretriz de número 23 e se encerra na de número 25 . Nesse eixo é refletido e afirmado a importância da memória e da verdade como princípios históricos dos Direitos Humanos. Sua finalidade é assegurar o processamento democrático e republicano do que aconteceu durante o regime militar, além de reparações as violações que tenham ocorrido naquela época.

Este documento não é o único no conjunto de contribuições já existentes e a serem elaboradas com vistas a fundamentar o processo de formulação teórico-metodológica acerca da Educação em Direitos Humanos, mas este decreto, realizado a partir da ajuda de docentes e militantes de diferentes regiões do país, constrói um grande passo para o processo formulação das Diretrizes Gerais para Educação em Direitos Humanos.

\section{QUAL É O PAPEL DO GESTOR?}

O gestor e sua equipe pedagógica não podem fechar os olhos para os problemas que acontecem no dia a dia escolar. O gestor tem o dever e o trabalho de fazer os alunos desenvolverem o respeito, a tolerância, aceitar e promover as diversidades étnico-raciais, religiosas, geracionais, de gênero, de orientação sexual, de nacionalidade, de opção política, entre tantas outra. $\mathrm{O}$ gestor deve estar sempre preparado e atualizado com o que está em sua volta de orientações e recursos que se pode ser usado. A autora Heloisa Lück diz asserva que:

Em consequência, desenvolver, atualizar e rever permanentemente conhecimentos deve fazer parte do dia-a-dia do diretor escolar e de professores pretendentes a essa função, como um processo de capacitação em serviço, de modo que desenvolva 
competência para o desempenho efetivo das funções de direção escolar e colaboração com a sua realização. Conhecer, compreender e incorporar em suas ações os fundamentos e princípios da educação, assim como as determinações legais norteadoras dos processos educacionais constitui-se, portanto, uma das primeiras e contínuas preocupações do diretor escolar na busca de realizar um bom trabalho, no sentido de liderar e orientar sua escola para que seja feito de melhor forma e com competência sempre maior desempenhe o seu papel social, realizando seus objetivos educacionais. (LUCK 2000, p. 18 19 apud PERRENOUD 2000, p. 19).

A autora segue sua ideia afirmando ainda que deve se aprofundar e pensar qual seria este papel:

Também ainda, envolve-se no esforço de aprofundar a compreensão do significado da gestão escolar pela qual é responsável, sua abrangência, suas dimensões de atuação e estratégias de ação que contribuem para construir escolas eficazes. E nesse trabalho, será efetivo se construir um quadro de competências de gestão, correspondentes a um conjunto referencial básico caracterizado como um acordo entre diversas concepções da prática e um conjunto delimitado de problemas e funções educacionais que ocorrem na escola. (LUCK 2000, p. 18 e 19 apud PERRENOUD 2000, p. 19).

Neste sentido, a educação para os Direitos Humanos como afirma Aguirre demanda justamente a capacidade de empatia, identificação e solidariedade com o outro.

Educar para os DH é assumir o primeiro direito fundamental de ser pessoa, todo ser humano se converte em educador que promove os DH quando tem clareza crítica e equilibrar o tato ao questionar costumes e comportamentos pessoais e coletivos baseados na 
autodefesa frente aos demais, substituindo-os com a atitude de respeito, responsabilidade e colaboração. (AGUIRRE, Op. Cit. p. 2-3)

Pensando nesta postulação, vem o questionamento: como o gestor deve agir e o porquê o tema Direitos Humanos é importante para a formação do indivíduo?

$\mathrm{O}$ autor Benevides aborda a educação em direitos humanos pelo seu potencial transformador.

[...] pretende uma formação de uma escolaridade autônoma, preparada para a solidariedade e a tolerância. E é também a formação de pessoas dispostas e capazes para a mudança, para a transformação, muitas vezes a transformação radical no sentido de ir às raízes das condições socioeconômicas, das condições culturais e políticas da sociedade em que vivem e que muitas vezes negam e negligenciam os Direitos Humanos, a democracia e o compromisso com a paz. (BENEVIDES, 1997, p. 12)

Ou seja, todo gestor e educador deve promover este desenvolvimento de autonomia e consciência crítica em seus educandos, para poder formar cidadãos autônomos capazes de serem críticos e protagonistas de suas vidas e ideias, mas como fazer com que essas práticas se efetivem? Existe algum caminho que oriente os gestores?

Pode se promover o desenvolvimento dessas competências através de alguns encaminhamentos como oficinas pedagógicas na formação escolar desse profissional, enriquecendo os currículos escolares das IES no sentido de despertar para a compreensão e o amadurecimento dos egressos em relação aos Direitos Humanos.

Tais aprendizagens podem ser divididas em quatro dimensões: a científica, que seria basicamente, o que fazer; a parte teórica do conhecimento, no qual também ocorre toda a aprendizagem. A técnica, que seria o como fazer, as práticas metodológicas; os instrumentos que serão usados e os métodos a serem aplicados no percurso. A política que aborda a negociação, a equidade dos desejos, a área contemplativa do por que fazer; em que entra o papel da educação formal do indivíduo e todo o 
processo da educação social. E, por último, a social, quem pode fazer; essa área aborda o papel dos gestores e professores juntos com os pais e a comunidade, também abrange as "parcerias", que é nada mais que o papel dos profissionais em diversos âmbitos que colaborarão com as instituições educativas escolares e não escolares.

Mas para poder trabalhar a ideia de educar com a visão nos Direitos Humanos é preciso que a escola tenha seus propósitos definidos com clareza sobre aonde quer chegar. Alem disso, que possa desenvolver ações democráticas, que possam ajudar alunos e professores a conviverem com respeito ao próximo em suas diferenças e as diversidades de quaisquer forma possam ser compreendidas, toleradas, respeitadas e que as diversas áreas do conhecimento escolar / curricular se interdisciplinarizem na construção de um ambiente escolar mais coletivo e participativo onde as decisões são pautadas em diálogos democráticos e colaborativos.

Nesse cenário, de uma proposta democrática de escola, requer a direção do diretor escolar para que possa construir e desenvolver um repertório conceitual próprio da sua escola, sobre a educação e seu trabalho de liderança educacional, de modo que possa saber traduzir essa ideia em ações efetivas sobre o seu projeto político pedagógico, atingindo as aspirações das demandas existentes na realidade de sua escola.

Assim, seu projeto político pedagógico necessita seguir a ideia de educar segundo os direitos humanos. No PPP de sua escola os direitos humanos devem estar inseridos, como disciplinas obrigatórias ou optativas ou em projetos interdisciplinares em que ocorra a transversalidade neste documento. Essa transversalidade segundo Silva (2010, p. 53), "pressupõe um tratamento integrado das áreas e dos conteúdos trabalhados no currículo escolar, e um compromisso com as relações interpessoais e sociais com as questões que estão envolvidas nos temas dessa área" (SILVA, 2010, p. 53).

Vale lembrar que as Diretrizes Nacionais da Educação em Direitos Humanos (BRASIL, 2012) guiam os sistemas de ensinos e mostram como deve ser a introdução dos conhecimentos dos direitos humanos em todos os níveis escolares, que pode ser organizada de várias formas: a) da transversalidade relacionando os conteúdos com a área dos direitos humanos; b) do diálogo expondo as ideias aos componentes curriculares; c) como parte específica na organização curricular interna de uma 
disciplina, d) e de uma forma básica que coloque essas ideias, ou seja, como práticas diárias das aprendizagens nas disciplinas e/ou de forma interdisciplinar.

Entre estes pontos, é importante lembrar que, a inclusão do tema da Educação em Direitos Humanos como um norte para a elaboração dos seus PPP é indissociável, independente de qual seja sua forma de trabalhar seus conteúdos em suas matrizes escolares, sendo que tal "Norte" signifique o encaminhamento para que esses conteúdos e as vivências de direitos humanos relacionem-se com as ações da instituição, muito mais além do que atividade docente / discente.

Quando se trata em associar os processos de metodologia da Educação em Direitos Humanos deve se destacar algumas áreas importantes. Candau e Sacavino defendem a tese que:

não é possível dissociar a questão das estratégias metodológicas para educação em direitos humanos de uma visão político-filosófica, de uma concepção dos direitos humanos e do sentido de educar em direitos humanos, numa determinada sociedade e em um momento histórico concreto. As estratégias pedagógicas não são um fim em si mesmas. Estão sempre a serviço de finalidades e objetivos específicos que se pretende alcançar (2010, p. 133).

Dessa forma, é muito importante chamar a atenção para que a educação em direitos humanos se trate de um longo caminho a ser desenvolvido, que os princípios e fins da educação sejam realmente alcançados no formação de pessoas humanas. Nele precisa existir coerência entre os princípios e os seus fundamentos políticos-filosóficos e educativos-sociais.

Seguindo essa ideia, Candau e Sacavino (2010) destacam a importância de analisar as diferentes dimensões dos processos de ensino-aprendizagem: saber, sistematizar, ver, celebrar, comprometer-se e socializar.

Estas dimensões são concebidas de maneira integrada e inter-relacionadas. $\mathrm{O}$ ver refere-se à análise da realidade, o saber aos conhecimentos específicos re- 
lacionados ao tema desenvolvido, o celebrar à apropriação do trabalhado utilizando-se diferentes linguagens como simulações, dramatizações, músicas, elaboração de vídeos, etc. A sistematização supõe a construção coletiva que sintetiza os aspectos mais significativos assumidos por todo o grupo e o comprometer-se a identificação de atitudes e ações a serem realizadas. A socialização da experiência vivida no contexto em que se atua constitui a etapa final do processo. Uma estratégia metodológica que nos processos que vimos desenvolvendo é privilegiada, são as chamadas oficinas pedagógicas, concebidas como espaços de intercâmbio e construção coletiva de saberes, de análise da realidade, de confrontação de experiências, de criação de vínculos sócio-afetivos e de exercício concreto dos direitos humanos (2010, p. 134-135).

Contudo, a busca de uma melhor qualidade educacional, vai além dos esforços do gestor educacional escolar, mas se dará nos coletivos escolares e sociais na medida em que esse gestor tenha clareza das realidades e diversidades existentes em sua escola; que atue em uma liderança efetiva e eficaz pautada nos princípios democráticos, para promover a diálogos e discussões onde todos tenham, responsavelmente, o direito de vez e voz e assumam as ações de defesa dos direitos humanos. Na vida escolar, este é um processo que é compromisso de todos os envolvidos na escola. Devemos lutar e tomar frente nessa ideia de todas as formas possíveis, também é necessário lembrar que a temática da escola é promover o compromisso com a humanização do homem para uma sociedade mais democrática, justa e feliz.

\section{CONSIDERAÇÕES FINAIS}

Todo o conteúdo apresentado neste artigo tenta apresentar o papel do gestor na educação escolar e como ele está sempre interligado com os Direitos Humanos, que cada vez mais, vem sendo discutido e apresentado no âmbito escolar. Desta maneira este é um assunto que não se esgota, e que permite cada vez mais a interação da escola com os mais diversos 
segmentos da sociedade em novas e futuras discussões e possibilidades de conquistas destes direitos. Para tanto, as práticas colegiadas de debate e discussão são ricas para o levantamento das mazelas da escola, bem como possibilitam caminhos e compreensões da dinâmica escolar, onde o gestor estará atuando, para buscar junto aos seus pares, mecanismos de diálogos / sugestões e ferramentas para as soluções de problemas aos quais os direitos humanos estavam ausentes e/ou não assistidos.

É necessário que todos os que estão envolvidos no meio escolar: professores, gestores, alunos, pais e sociedade estejam sempre atualizados das legislações nacionais que promovem os Direitos Humanos, bem como de tantos fatos que ocorrem no seio escolar por falta de conhecimentos e informações que foram citadas no artigo, principalmente sobre a apuração das causas das mazelas sociais que mais aparecem nas dinâmicas sociais da escola e que são excludentes, para que possam saber como agir perante as situações sobre as quais venham a acontecer no seu dia a dia, quais informações deverão promover aos estudantes para que seus direitos sejam garantidos e respeitados como cidadãos; como debelar conflitos entre os pares "alunos/alunos", "alunos/professores", "professores/administração", "alunos/administração" para que haja harmonia no ambiente educativo, promovendo mais qualidade no processo ensino-aprendizagem; como tratar e encaminhar situações que vão além das possibilidades gestoras do diretor da escola e de sua equipe; como buscar parcerias para implementação de capacitação dos educadores, entre tantos outros recursos necessários que garantirão os direitos básicos.

Sabendo os seus direitos e os seus deveres gestores, professores, alunos e comunidade interna e externa escolar - famílias e comunidades compreenderão que ao assumirem conjuntamente a responsabilidade sobre o ensino e a educação, todo o processo escolar passa a se tornar mais democrático, quando bem encaminhado, quando os poderes forem divididos por meio de uma liderança democrática e os direitos humanos serem aplicados, realizados e efetivados, as inter-relações entre os protagonistas escolares se tornam mais dignas e justas.

Considerando todas essas ideias e informações fica evidente o pensamento de que o desenvolvimento de uma educação / escola de qualidade não poderá permitir que as mazelas sociais perpetuadas na sociedade sejam reproduzidas nas escolas, mas que cada vez mais se busque 
uma educação que quebre com os preconceitos e que busque o desenvolvimento e a formação para as humanidades. Além disso, que se formem seus alunos para uma visão democrática de mundo, que possibilitará ainda a eles, conceitos baseados na promoção humana para se autoconstruir um indivíduo pronto para viver na sociedade. Isso possibilitará aos alunos saberem se expressar e respeitar o seu próximo, saber quais são os seus direitos e deveres. Portanto, de uma educação de qualidade e de um olhar diferenciado do gestor educacional se busca conduzir o processo educativo com atitudes dialógicas, que não permitam aos futuros cidadãos sejam alienados ou manipulados por seus governantes.

Mesmo sabendo que esse processo será lento; é dever dos educadores e da sociedade em geral, desenvolver mobilizações para que as ideias dos Direitos Humanos possam ser apresentadas e se concretizem, de verdade, em nosso cenário brasileiro e no mundo.

\section{REFERÊNCIAS}

AGUIRRE, L. P. Educar para os direitos humanos: o grande desafio contemporâneo. São Paulo. Rede Brasileira de Educação em Direitos Humanos. s/d. (mimeo).

BENEVIDES, M. V. Educação, democracia e direitos humanos. In: Jornal da Rede. São Paulo: Rede Brasileira de Educação em Direitos Humanos, No. 1, Maio de 1997.

. I Congresso da Rede. São Paulo: Rede Brasileira de Educação em Direitos Humanos. Edição Especial, No. 02, Setembro de 1997.

BRASIL. Constituição da República Federativa do Brasil (1988). 11. ed. São Paulo: Ridel, 2005.

BRASIL. Lei n. 9.394, de 20 de dezembro de 1996. Lei de Diretrizes e Bases da Educação Nacional. Estabelece as diretrizes e bases da educação nacional. Diário Disponível em: http://www.planalto.gov.br/ccivil_03/ Leis/L9394.htm Acesso em: 22jun.2016.

CANDAU, V. M.; SACAVINO, S. Educação em Direitos Humanos: 
concepções e metodologias. In: FERREIRA, Lúcia de Fátima Guerra et al. (Orgs.). Direitos Humanos na Educação Superior: Subsídios para a Educação Superior em Direitos Humanos na Pedagogia. João Pessoa: Editora Universitária da UFPB, 2010.

CARNEIRO, A. de A. C. Plano nacional dos direitos humanos. Revista Jus Navigandi, Teresina, ano 15, n. 2406, 1 fev.2010. Disponível em: $<$ https://jus.com.br/artigos/14275>. Acesso em: 22jun.2016.

DEMO, P. Desafios modernos da educação. Petrópolis, R.J.: Vozes, 2000 .

GANDIN, D. A Prática do Planejamento Participativo: na educação e em outras instituições, grupos e movimentos dos campos: cultural, social, político, religioso e governamental. Petrópolis, R.J.: Vozes, 2000.

LÜCK, H. Dimensões da gestão escolar e suas competências. Curitiba: Editora Positivo, 2009.

PARO, V. H. Gestão democrática da escola pública. São Paulo: Ed. Ática, 1998.

SILVA, A. M. M. Direitos humanos na educação básica: qual o significado? In: SILVA, Aida. M. M.; TAVARES, Celma (Orgs.). Políticas e fundamentos da educação em direitos humanos. São Paulo: Cortez, 2010.

ZENAIDE, M. de N. T. Globalização, Educação em Direitos Humanos e Currículo. Revista Eletrônica Espaço do Currículo, João PessoaPB, ano 1, $\mathrm{n}^{\mathrm{o}}$. 1, abril 2008. Disponível em: http://www.aepppc.org.br/ revista/. Acesso em: 22jun.2016.

Recebido em: 28/06/2018

Aceito em: 30/07/2018 